\title{
Long-term oncological results after transanal total mesorectal excision for rectal carcinoma
}

\author{
Jeroen C. Hol ${ }^{1}\left[\right.$. Stefan E. van Oostendorp ${ }^{2}(\mathbb{D}) \cdot$ Jurriaan B. Tuynman ${ }^{2}\left(\mathbb{D} \cdot\right.$ Colin Sietses $^{1}[$
}

Received: 9 June 2019 / Accepted: 12 September 2019 / Published online: 10 October 2019

(c) The Author(s) 2019

\begin{abstract}
Background Transanal total mesorectal excision (TaTME) for mid and low rectal cancer has been shown to improve shortterm outcomes, mostly due to lower conversion rates and with improved quality of the specimen. However, robust long-term oncological data supporting the encouraging clinical and pathological outcomes are lacking.

Methods All consecutive patients undergoing TaTME with curative intent for mid or low rectal cancer in two referral centers in The Netherlands between January 2012 and April 2016 with a complete and minimum follow-up of 36 months were included. The primary outcome was local recurrence rate. Secondary outcomes were disease-free survival, overall survival and development of metastasis.

Results There were 159 consecutive patients. Their mean age was $66.9(10.2)$ years and $66.7 \%$ of all patients were men. Pathological analysis showed a complete mesorectum in 139 patients $(87.4 \%)$, nearly complete in $16(10.1 \%)$ and an incomplete mesorectum in $4(2.5 \%)$. There was involvement of the CRM $(<1 \mathrm{~mm})$ in one patient $(0.6 \%)$ and no patients had involvement of the distal margin $(<5 \mathrm{~mm})$. Final postoperative staging after neoadjuvant therapy was stage 0 in 11 patients $(6.9 \%)$, stage I in $73(45.9 \%)$, stage II in $31(19.5 \%)$, stage III in $37(23.3 \%)$ and stage IV in $7(4.4 \%)$. The 3 -year local recurrence rate was $2.0 \%$ and the 5-year local recurrence rate was 4.0\%. Median time to local recurrence was 19.2 months. Distant metastases were found in $22(13.8 \%)$ patients and were diagnosed after a median of 6.9 months (range 1.1-50.4) months. Disease-free survival was $92 \%$ at 3 years and $81 \%$ at 5 years. Overall survival was $83.6 \%$ at 3 years and $77.3 \%$ at 5 years.

Conclusions The long-term follow-up of the current cohort confirms the oncological safety and feasibility of TaTME in two high volume referral centers for rectal carcinoma. However, further robust and audited data must confirm current findings before widespread implementation of TaTME.
\end{abstract}

Keywords Colorectal cancer · Long-term results $\cdot$ Transanal TME

\section{Introduction}

Transanal total mesorectal excision (TaTME) has the potential to lower the local recurrence rate after radical resection of mid and low rectal cancer. Currently available evidence shows an improvement in the quality of the surgical specimen and reduced number of $\mathrm{R} 1$ resections with longer distal margins in initial cohort studies [1-3]. Therefore, TaTME

Jeroen C. Hol

HolJ@zgv.nl

1 Department of Surgery, Gelderse Vallei Hospital, P.O. Box 9025, 6710 HN Ede, The Netherlands

2 Department of Surgery, Amsterdam University Medical Center, Location VUmc, Cancer Center, Amsterdam, The Netherlands has the potential to lower the local recurrence rate after radical resection of mid and low rectal cancer. However, longterm data on local recurrence rates confirming encouraging pathological outcomes are lacking [4]. Over the past decades, adoption of total mesorectal excision (TME) as the surgical principle has reduced local recurrence rates and improved cancer-free survival rates [5]. Combined with neoadjuvant chemoradiation, the local recurrence rates have been reduced to $5 \%$ as demonstrated in a large randomized clinical trial [6].

Even though laparoscopic surgery has improved the short-term results of rectal cancer surgery, large randomized trials have shown that the oncological benefits are modest [6-8]. Laparoscopic TME is a difficult technique and this may negatively influence the results of surgery, especially as regards the lower part of the rectum In male patients with a 
small narrow pelvis, there is a limited space to mobilize the rectum with intact mesorectum.

In TaTME, the rectum is approached both from above and below, preferably at the same time [1]. Because the distal part of the rectum is approached from below, it is more accessible and the surgical planes are better visualized. The technique appears to be feasible and short-term outcomes seem promising in expert centers. However, the learning curve is steep, which might influence the results in low volume centers [3, 9]. Recently, the local recurrence rate after TaTME in Norway was reported to be $9.5 \%$ which led to a nationwide stop of TaTME and thorough investigation [10]. The results of the official investigations are eagerly awaited. Other single center series have reported local recurrence rates ranging from 2.3 to $5.7 \%$ with a median follow-up of 15-32 months [2,11-15]. The aim of this study was to investigate the long-term oncological results after TaTME surgery in a large consecutive cohort from the two hospitals that started TaTME in The Netherlands with a minimum follow-up of 36 months.

\section{Materials and methods}

\section{Patients}

Between January 2012 and May 2016, all patients in the Gelderse Vallei Hospital, Ede, The Netherlands and Amsterdam UMC, location VUmc, Amsterdam, The Netherlands with histological proven distal or mid rectal carcinomas, who had elective TaTME, were included. Exclusion criteria were recurrent and/or locally advanced tumors with persistent threatened margins after neoadjuvant radiotherapy and palliative resections. Patients with curative resection of synchronous liver metastasis were included.

Preoperative assessment included magnetic resonance imaging (MRI) for local staging, computed tomography (CT) scan of the abdomen, CT scan or conventional X-ray of the chest to detect distant metastasis, and blood tests including serum carcinoembryonic antigen (CEA) levels. Each patient was discussed by a local multidisciplinary cancer board. Patients at medium risk, i.e., those with cT3b+ N0 or cT2-3 N1 tumors received preoperative radiotherapy with 5 Gy daily for five consecutive days. Patients with N2 disease or tumors with threatened margins $(<1.0 \mathrm{~mm})$ to the mesorectal fascia were treated with chemoradiation therapy for 25 days with 2 Gy daily combined with administration of oral 5-fluorouracil.

The study was approved by the Ethics Committees of the participating centers. All procedures performed in studies involving human participants were in accordance with the ethical standards of the institutional and/or national research committee and with the 1964 Helsinki Declaration and its later amendments or comparable ethical standards.

\section{Surgical procedure}

TaTME was performed as described previously [2]. The first patients were operated on by a single surgeon, performing both phases of the procedure sequentially. After the initial learning curve, the two team approach was introduced, with simultaneous abdominal and the transanal dissection. The splenic flexure was mobilized in the majority of the patients. Ligation of the inferior mesenteric vein was done near the pancreas.

The transanal phase consists of a thorough washout and the introduction of the anal platform; in the majority of the cases the GelPOINT Path Transanal Access Platform (Applied Medical, Rancho Santa Margarita, CA, USA) was used. In the first patients, a regular laparoscopic $\mathrm{CO}_{2}$ insufflator was used. In all other patients, the AirSeal insufflator (ConMed, Utica, NY, USA) was used. The purse-string location changed from the initial position directly behind the dentate line to a $3 \mathrm{~cm}$ higher position above the anorectal junction (if applicable for the location of the tumor, in proximal tumors it was placed below the tumor). Dissection was performed in a standardized fashion, starting the dissection dorsally and ventrally and thereafter dissecting the lateral plane. The abdominal and transanal team joined anteriorly. Specimen extraction was performed, after wound protection, through a Pfannenstiel incision. The anastomosis was preferably made side to end using a 31 EEA or 33 EEA hemorrhoid stapler (Medtronic, Dublin, Ireland).

\section{Data collection}

Baseline data were collected regarding age, sex, American Society of Anesthesiologists (ASA) classification, body mass index (BMI), distance of the tumor from the anal verge, preoperative clinical staging and preoperative chemoradiation therapy. Pathological outcomes included pathological staging, macroscopic completeness of the resection, number of lymph nodes harvested and circumferential resection margin (CRM) involvement. All patients have had follow-up carried out according to the Dutch National Guidelines for Colorectal Cancer for a period of 5 years at the outpatient clinic. For this cohort, a full 36-month follow-up was available for all patients. Primary outcome was locoregional recurrence. Secondary outcomes included distant metastasis, disease-free and overall survival. Recurrent disease was defined as the presence of locoregional recurrence, distant metastases or death from rectal cancer. 


\section{Statistical analysis}

All data collection and statistical analysis were carried out using SPSS Statistics version 24 (IBM, Chicago, IL, USA). After analysis of numbers and percentages or median and range for each variable, a univariate binary regression analysis was performed for possible risk factors for local recurrence. Kaplan-Meier survival analysis was performed for local recurrence-free survival rates, disease-free survival rates and overall survival rates.

\section{Results}

\section{Patient characteristics and clinical outcomes}

From January 2012 to May 2016, a total of 159 consecutive patients underwent TaTME. 110 underwent surgery in Gelderse Vallei Hospital, Ede, The Netherlands, and 49 in Amsterdam UMC, location VUmc, Amsterdam, the Netherlands. Their mean age was $66.9(10.2)$ years and $66.7 \%$ of all patients were men. The follow-up data for 36-month followup was complete for all patients. Neoadjuvant radiotherapy was administered in 112 patients (70.4\%) and 117 received a primary anastomosis during surgery (73.6\%). Thirty-nine patients $(24.5 \%)$ encountered postoperative complications graded as Clavien-Dindo grade 3 or higher. Patient characteristics and short-term clinical outcomes are summarized in Table 1.

\section{Oncologic outcomes}

Pathological analysis showed a complete mesorectum in 139 patients $(87.4 \%)$, nearly complete in $16(10.1 \%)$ and an incomplete mesorectum in 4 (2.5\%). There was involvement of the CRM $(<1 \mathrm{~mm})$ in one patient $(0.6 \%)$ and no patients had involvement of the distal margin $(<5 \mathrm{~mm})$.

Pathological staging showed T0 in 13 patient (8.2\%), T1 in $15(9.4 \%), \mathrm{T} 2$ in $74(46.5 \%), \mathrm{T} 3$ in $55(34.6 \%)$ and $\mathrm{T} 4$ in $2(1.3 \%)$. $\mathrm{N}$ stage was $\mathrm{N} 0$ in 118 patients $(74.2 \%), \mathrm{N} 1$ in $28(17.6 \%)$ and N2 in $13(8.2 \%)$. Final postoperative staging after neoadjuvant therapy according to the fifth AJCC classification was stage 0 in 11 patients $(6.9 \%)$, stage I in 73 (45.9\%), stage II in 31 (19.5\%), stage III 37 (23.3\%) and stage IV in 7 (4.4\%).

The mean long-term follow-up was 54.8 months (range 36-88 months). The overall local recurrence rate was 3.8\%, and median time to local recurrence was 19.2 months (range 5.9-30.0 months). Figure 1 shows a Kaplan-Meier (KM) curve of local recurrence. The local recurrence rate was $2.0 \%$ at 3 years and $4.0 \%$ at 5 years. An overview of all six cases of local recurrence and treatment can be seen in Table 2.
Table 1 Patient characteristics and clinical outcome

\begin{tabular}{|c|c|}
\hline & $n=159$ \\
\hline \multicolumn{2}{|l|}{ Sex } \\
\hline Male & $106(66.7)$ \\
\hline Female & $53(33.3)$ \\
\hline BMI (mean) $( \pm \mathrm{SD})$ & $26.4(4.3)$ \\
\hline Age (years) (mean) $( \pm \mathrm{SD})$ & $66.9(10.2)$ \\
\hline \multicolumn{2}{|l|}{ ASA } \\
\hline I & $33(20.8)$ \\
\hline II & $100(62.9)$ \\
\hline III & $26(16.4)$ \\
\hline \multicolumn{2}{|l|}{ Height from AV $(\mathrm{cm})$} \\
\hline Mean $( \pm S D)$ & $5.7(3.5)$ \\
\hline Median (range) & $6(0-15)$ \\
\hline \multicolumn{2}{|l|}{ Height from $\mathrm{AV}<4 \mathrm{~cm}$} \\
\hline Yes & 47 (29.6) \\
\hline \multicolumn{2}{|l|}{ Clinical tumor stage } \\
\hline $\mathrm{T} 1$ & $2(1.3)$ \\
\hline $\mathrm{T} 2$ & $39(24.5)$ \\
\hline $\mathrm{T} 3$ & $103(64.8)$ \\
\hline $\mathrm{T} 4$ & $11(6.9)$ \\
\hline $\mathrm{Tx}$ & $4(2.5)$ \\
\hline \multicolumn{2}{|l|}{ Clinical nodal stage } \\
\hline No & $82(51.6)$ \\
\hline N1 & $47(29.6)$ \\
\hline $\mathrm{N} 2$ & $26(16.4)$ \\
\hline $\mathrm{Nx}$ & $3(1.9)$ \\
\hline \multicolumn{2}{|l|}{ Synchronous metastasis } \\
\hline $\mathrm{M}+$ & $7(4.4)$ \\
\hline \multicolumn{2}{|l|}{ MRF threatened (before RT) } \\
\hline No & 125 (78.6) \\
\hline Yes & $34(21.4)$ \\
\hline \multicolumn{2}{|l|}{ Preoperative therapy } \\
\hline RT & $112(70.4)$ \\
\hline CRT & $43(27.0)$ \\
\hline \multicolumn{2}{|l|}{ Anastomosis } \\
\hline Primary anastomosis & $117(73.6)$ \\
\hline End colostomy & $42(26.4)$ \\
\hline \multicolumn{2}{|l|}{ Performed operation } \\
\hline LAR TaTME & $133(83.6)$ \\
\hline ISR/APE TaTME & $26(16.4)$ \\
\hline \multicolumn{2}{|l|}{ Intraoperative complications } \\
\hline Rectal perforation & $2(1.3)$ \\
\hline Purse-string failure & $1(0.6)$ \\
\hline Carbon dioxide $\left(\mathrm{CO}_{2}\right)$ embolus & $1(0.6)$ \\
\hline \multicolumn{2}{|l|}{ Postoperative morbidity } \\
\hline No complications & $46(47.8)$ \\
\hline Minor Clavien-Dindo 1-2 & $44(27.7)$ \\
\hline Severe Clavien-Dindo $\geq 3$ & $39(24.5)$ \\
\hline Reoperation & $36(22.6)$ \\
\hline Anastomotic leakage & $10(6.3)$ \\
\hline Presacral abscess & $14(8.8)$ \\
\hline
\end{tabular}

Numbers in parentheses are percentages, unless mentioned otherwise $B M I$ body mass index $\left(\mathrm{kg} / \mathrm{m}^{2}\right), S D$ standard deviation, $A S A$ American Society of Anesthesiologists, $\mathrm{cm}$ centimeters, $A V$ anal verge, $M R F$ 
Table 1 (continued)

mesorectal fascia, $R T$ radiotherapy, $C R T$ chemoradiotherapy, $L A R$ low anterior resection, ISR intersphincteric resection, $A P E$ abdominoperineal excision, $T x$ or $N x$ means stage unknown based on preoperative MRI

Disease-free survival was $92 \%$ at 3 years and $81 \%$ at 5 years. Figure 2 shows a Kaplan-Meier curve of diseasefree survival. Distant metastases were found in 22 (13.8\%) patients and were diagnosed after a median of 6.9 months (1.1-50.4). Two out of six patients with local recurrence had concomitant distant metastasis. Overall survival was $83.6 \%$ at 3 years and at $77.3 \% 5$ years. Figure 3 shows a Kaplan-Meier curve of overall survival. The pathology results and long-term results are summarized in Table 3.

\section{Risk factors for local recurrence}

Univariate binary logistic regression analysis for local recurrence showed no significant difference for sex, obesity, low tumor, threatened mesorectal fascia, preoperative radiotherapy, (y)pT4 stage, (y)pN2 stage, positive CRM, incomplete mesorectum, intraoperative perforation, intraoperative purse-string failure, carbon dioxide embolus, synchronous metastasis, anastomotic leakage and reoperation. There was a significant risk for pathologic stage T3 or 4 tumors, RR 0.103 (0.012-0.904), $p=0.040$, complications grade 3 or higher according to Clavien-Dindo RR 0.148 $(0.026-0.844), p=0.031$ and presence of presacral abscess RR $0.077(0.014-0.430), p=0.003$. The patient with intraoperative purse-string failure did not develop presacral abscess or local recurrence. Results of the univariate analysis for risk factors are summarized in Table 4.
Fig. 1 Kaplan-Meier curve of local recurrence-free survival after TaTME

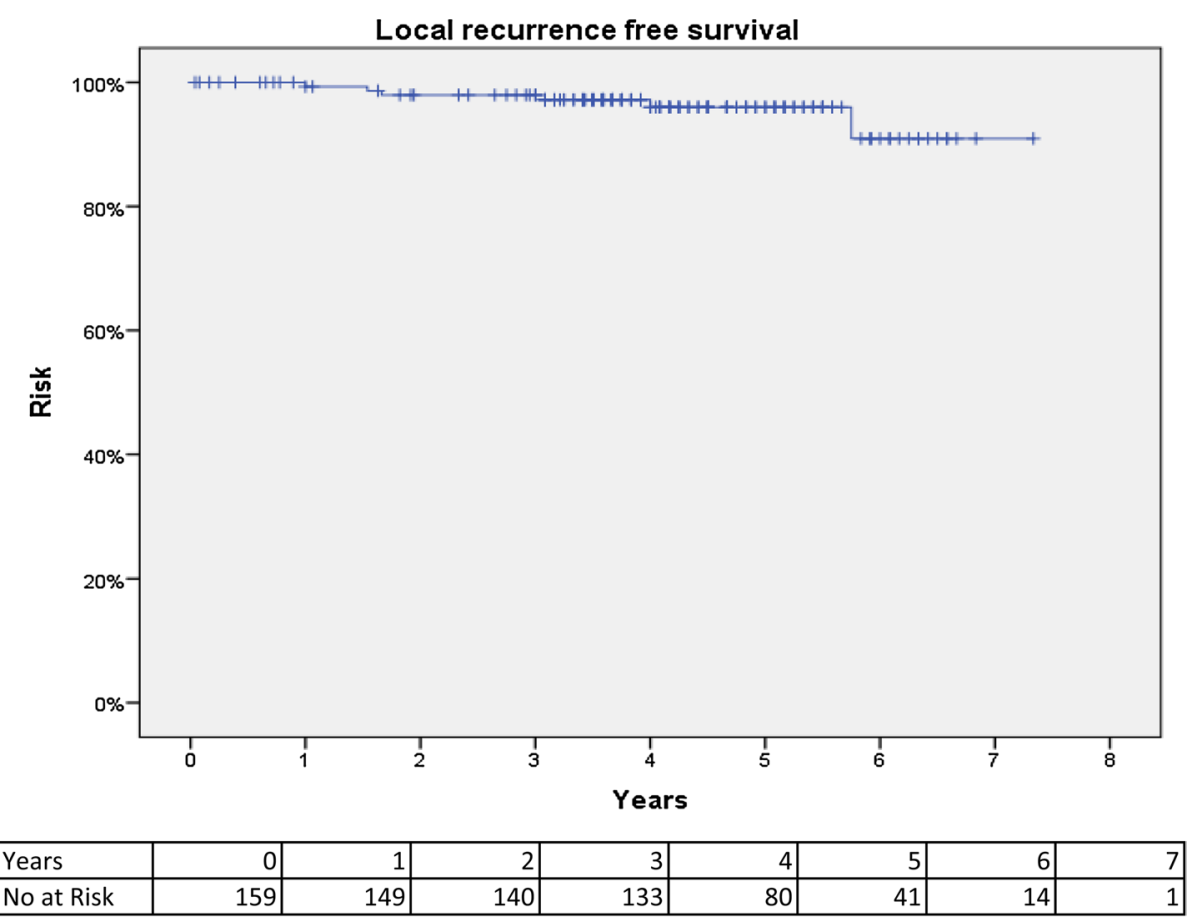

Table 2 Overview of cases with local recurrence

\begin{tabular}{lllllclll}
\hline Surgery & p Stage & Complications & R & Neoadjuvant & $\begin{array}{l}\text { Interval } \\
\text { (months) }\end{array}$ & Location & Treatment & Survival \\
\hline 2012 & T3N2 & Presacral abscess & R0 & Radiotherapy & 18 & Presacral & Palliative chemotherapy & 57 months \\
2013 & T2N1 & None & R0 & None & 8 & Presacral & Stoma and palliative chemotherapy & Alive, remission \\
2014 & T3N0 & Presacral abscess & R1 & Chemoradiation & 6 & Presacral & Palliative treatment & 12 months \\
2016 & T3N0 & Anastomotic leakage & R0 & Chemoradiation & 30 & Presacral & APE & Alive \\
2014 & ypT0N0 & Presacral abscess & R0 & Radiotherapy & 19 & Vesiculae & APE and debulking & Alive \\
2015 & pT3N1 & None & R0 & None & 27 & Presacral & CRTX, exenteration & Alive \\
\hline
\end{tabular}

$A P E$ abdominoperineal excision, $C R T X$ chemoradiation therapy 
Fig. 2 Kaplan-Meier curve of disease-free survival after TaTME

Fig. 3 Kaplan-Meier curve of overall survival after TaTME
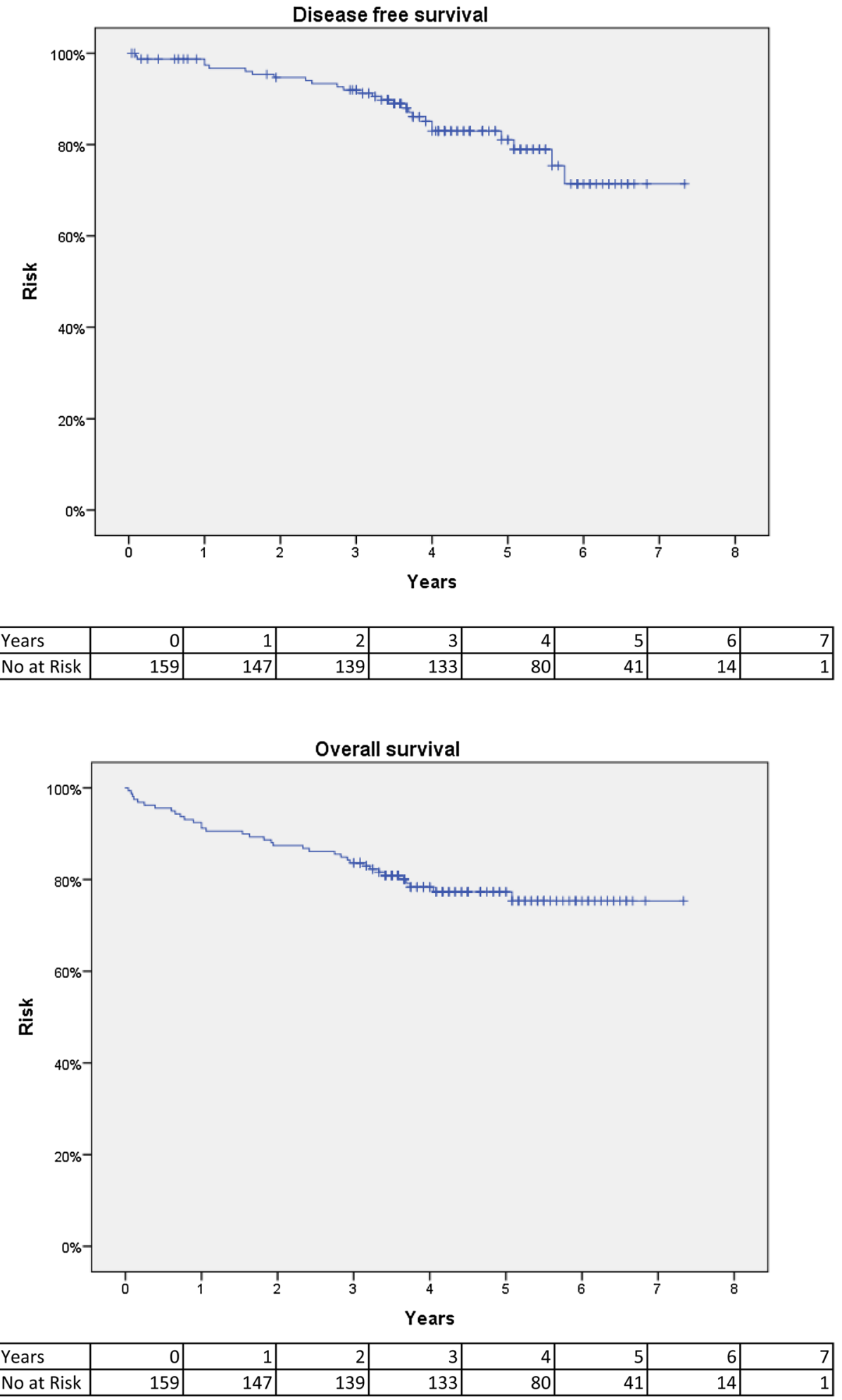

\section{Discussion}

This study of 159 TaTME procedures for rectal cancer shows that TaTME is associated with low local recurrence rate; the 3-year local recurrence rate was $2.0 \%$ with complete follow-up and the 5-year local recurrence rate was $4.0 \%$. The median time to local recurrence was 19.2 months (range 5.9-30.0 months). To the best of our 
Table 3 Pathologic and long-term outcomes

\begin{tabular}{|c|c|}
\hline & $n=159$ \\
\hline \multicolumn{2}{|l|}{ Pathologic T-stage } \\
\hline (y)pT0 & $13(8.2)$ \\
\hline (y)pT1 & $15(9.4)$ \\
\hline (y)pT2 & $74(46.5)$ \\
\hline (y)pT3 & $55(34.6)$ \\
\hline (y)pT4 & $2(1.3)$ \\
\hline \multicolumn{2}{|l|}{ Pathologic N stage } \\
\hline No & $118(74.2)$ \\
\hline N1 & $28(17.6)$ \\
\hline $\mathrm{N} 2$ & $13(8.2)$ \\
\hline \multicolumn{2}{|c|}{ Quality of specimen (Quirke) } \\
\hline Incomplete & $4(2.5)$ \\
\hline Nearly complete & $16(10.1)$ \\
\hline Complete & $139(87.4)$ \\
\hline \multicolumn{2}{|l|}{$\mathrm{CRM}+$} \\
\hline$<1 \mathrm{~mm}$ & $1(0.6)$ \\
\hline \multicolumn{2}{|l|}{ DRM+ } \\
\hline$<5 \mathrm{~mm}$ & $0(0.0)$ \\
\hline \multicolumn{2}{|l|}{ Follow-up (months) } \\
\hline Mean $( \pm \mathrm{SD})^{*}$ & $54.8(13.1)$ \\
\hline Median (range)* & $52.0(36.0-88.0)$ \\
\hline \multicolumn{2}{|c|}{ Local recurrence overall } \\
\hline No & $153(96.2)$ \\
\hline Yes & $6(3.8)$ \\
\hline \multicolumn{2}{|c|}{ Interval to local recurrence (months) } \\
\hline Median (range) & $19.2(5.9-30.0)$ \\
\hline \multicolumn{2}{|l|}{ Distant metastasis } \\
\hline No & $137(86.2)$ \\
\hline Yes & $22(13.8)$ \\
\hline \multicolumn{2}{|c|}{ Interval to distant metastasis (months) } \\
\hline Median (range) & $6.9(1.1-50.4)$ \\
\hline \multicolumn{2}{|l|}{ Disease recurrence } \\
\hline No & $133(83.6)$ \\
\hline Yes & $26(16.4)$ \\
\hline \multicolumn{2}{|c|}{ Interval to disease recurrence } \\
\hline Months & $8.2(1.1-50.4)$ \\
\hline Overall survival & $124(78.0)$ \\
\hline Deceased & $35(22.0)$ \\
\hline \multicolumn{2}{|c|}{ Interval to death (months) } \\
\hline Median (range) & $28.0(0.5-61)$ \\
\hline
\end{tabular}

Numbers in parentheses are percentages, unless mentioned otherwise

*Mean/median range does not include diseased patients

knowledge this is the largest series with a complete and long follow-up of more than 3 years after TaTME.

The 3-year local recurrence rate in this study is relatively low compared to the laparoscopic TME long-term outcome data of the COLOR II, ALaCART and ACOSOG Z6051 trials, which show a 3-year local recurrence rate of 5\% [6-8].
In accordance with previous literature, high tumor stage, severe postoperative complications and presence of a presacral abscess were risk factors for local recurrences [16]. A multivariate analysis was not possible due to the low number of events.

One of the potential benefits of TaTME for mid and low rectal cancer is a better specimen quality and better radicality. Incomplete mesorectum is a known risk factor for local and overall recurrence [17]. In our study, $97.5 \%$ of the specimens were of good quality, comparable to our previous study in which $100 \%$ of the specimens after TaTME were of good quality, while in the traditional laparoscopic group $80 \%$ were of good quality [18].

Although TaTME was introduced in 2010, ample data on long-term outcome are currently limited. In contrast, a considerable amount of case series describing single center experiences focus merely on short-term and pathological outcomes [19]. Although there is a growing interest in TaTME in rectal cancer surgery, it is still not widely implemented and concerns persist regarding the adequacy of oncological resection. Our study adds long-term outcome data to support the potential benefits of TaTME for mid and low rectal cancer: increased quality of the mesorectum, low number of positive CRM and corresponding low local recurrence rate.

Although the results from our study are encouraging, it only includes data from the two hospitals that started TaTME in The Netherlands which are high volume tertiary referral centers. The oncological results of widespread adoption of TaTME have not yet been demonstrated. Early adopters of TaTME recognized the high complexity of the procedure [20]. Therefore, several countries started a nationwide structured training program including proctoring to guarantee safe implementation of the procedure [21, 22]. The technique has a learning curve associated with substantial morbidity. Surgeons have to perform at least 40 cases to reach competency, based on acceptable morbidity or good pathologic outcome [9, 23]. Furthermore, higher volumes are associated with better outcome in terms of conversion, severe complications and quality of the mesorectum [3]. Our results do not support the concern that TaTME leads to an increased risk for local recurrence, as suggested by Norwegian data [10]. It is to be imagined that poor quality TaTME does negatively influence local recurrence rates. A review focusing on outcomes of TaTME in low volume centers was associated with a relatively high recurrence rate of $8.9 \%$ versus $2.8 \%$ in high volume centers [3].

This indicates that a steep learning curve might seriously hamper both short- and long-term outcome. Inadequate dissection, perforation and/or insufficient closure of the rectum before dissection all have the potential for tumor spill [24].

The Idea, Development, Exploration, Assessment and Long-term follow-up (IDEAL) framework aims to prevent 
Table 4 Univariate analysis of risk factors for local recurrence

\begin{tabular}{|c|c|c|c|c|c|c|}
\hline & LR & Total & $\mathrm{RR}$ & $95 \%$ CI lower & $95 \%$ CI upper & $P$ value \\
\hline \multicolumn{7}{|l|}{ Sex } \\
\hline Female & 3 & 53 & Ref & & & \\
\hline Male & 3 & 106 & 2.06 & 0.401 & 10.573 & 0.386 \\
\hline \multicolumn{7}{|l|}{$\mathrm{BMI}>25$} \\
\hline No & 4 & 66 & Ref & & & \\
\hline yes & 2 & 93 & 2.935 & 0.522 & 16.522 & 0.222 \\
\hline \multicolumn{7}{|c|}{ Low tumor $<4 \mathrm{~cm}$ from $\mathrm{AV}$} \\
\hline No & 4 & 112 & Ref & & & \\
\hline Yes & 2 & 47 & 0.833 & 0.147 & 4.713 & 0.837 \\
\hline \multicolumn{7}{|c|}{ MRF threatened on MRI } \\
\hline No & 4 & 125 & Ref & & & \\
\hline Yes & 2 & 34 & 0.529 & 0.093 & 3.018 & 0.473 \\
\hline \multicolumn{7}{|c|}{ Preoperative radiotherapy } \\
\hline No & 2 & 47 & Ref & & & \\
\hline Yes & 4 & 112 & 1.200 & 0.212 & 6.787 & 0.837 \\
\hline \multicolumn{7}{|c|}{ Pathologic stage T3-4 } \\
\hline No & 1 & 102 & Ref & & & \\
\hline Yes & 5 & 57 & 0.103 & 0.012 & 0.904 & 0.040 \\
\hline \multicolumn{7}{|c|}{ Pathologic stage T4 } \\
\hline No & 6 & 157 & Ref & & & \\
\hline Yes & 0 & 2 & & 0.000 & & 0.999 \\
\hline \multicolumn{7}{|c|}{ Pathologic stage N2 } \\
\hline No & 5 & 146 & Ref & & & \\
\hline Yes & 1 & 13 & 0.426 & 0.046 & 3.943 & 0.452 \\
\hline \multicolumn{7}{|l|}{$\mathrm{CRM}+$} \\
\hline No & 5 & 158 & Ref & & & \\
\hline Yes & 1 & 1 & 0.000 & 0.000 & & 1.000 \\
\hline \multicolumn{7}{|c|}{ Incomplete mesorectum } \\
\hline No & 6 & 155 & Ref & & & \\
\hline Yes & 0 & 4 & & 0.000 & & 0.999 \\
\hline \multicolumn{7}{|c|}{ Intraoperative perforation } \\
\hline No & 6 & 157 & Ref & & & \\
\hline Yes & 0 & 2 & & 0.000 & & 0.999 \\
\hline \multicolumn{7}{|c|}{ Purse-string failure } \\
\hline No & 6 & 158 & Ref & & & \\
\hline Yes & 0 & 1 & & 0.000 & & 1.000 \\
\hline \multicolumn{7}{|c|}{$\mathrm{CO}_{2}$ embolus } \\
\hline No & 6 & 158 & Ref & & & \\
\hline Yes & 0 & 1 & & 0.000 & & 1.000 \\
\hline \multicolumn{7}{|c|}{ Synchronous metastasis } \\
\hline No & 5 & 152 & Ref & & & \\
\hline Yes & 1 & 7 & 0.204 & 0.021 & 2.029 & 0.175 \\
\hline \multicolumn{7}{|c|}{ Complications CD 3 or higher } \\
\hline No & 2 & 120 & Ref & & & \\
\hline Yes & 4 & 39 & 0.148 & 0.026 & 0.844 & 0.031 \\
\hline \multicolumn{7}{|c|}{ Anastomotic leakage } \\
\hline No & 5 & 149 & Ref & & & \\
\hline Yes & 1 & 10 & 0.313 & 0.033 & 2.965 & 0.311 \\
\hline \multicolumn{7}{|c|}{ Presacral abscess } \\
\hline No & 3 & 145 & Ref & & & \\
\hline Yes & 3 & 14 & 0.077 & 0.014 & 0.430 & 0.003 \\
\hline \multicolumn{7}{|c|}{ Reoperation } \\
\hline No & 3 & 123 & Ref & & & \\
\hline Yes & 3 & 36 & 0.275 & 0.053 & 1.426 & 0.124 \\
\hline
\end{tabular}


Table 4 (continued)

$B M I$ body mass index $\left(\mathrm{kg} / \mathrm{m}^{2}\right), A V$ anal verge, $M R F$ mesorectal fascia, $C R M+$ involvement of the circumferential resection margins $(<1 \mathrm{~mm}), C D$ Clavien-Dindo

surgical innovation from being implemented too early [25]. While the TaTME is still in the developmental stage and no global consensus and standardization has been reached, one could argue that the surgical community has proceeded to the adoption of this technique too early. This means exposing patients to potential intraoperative complications and short-term morbidity. Furthermore, long-term oncological safety of the technique must be established to avoid events comparable to the port-site metastasis setback seen in laparoscopic surgery [26]. The international TaTME registry is a useful instrument for capturing real-time data of the early adoption of TaTME and has signaled a $15.7 \%$ anastomotic failure rate [27]. The long-term follow-up data of the international registry are awaited, although the completeness of data will be a potential problem and source of bias.

Although the results of our study are promising, oncological safety after TaTME surgery remains to be proven in a multicenter international setting. The next crucial step in implementing this technique is an international randomized controlled trial such as the COLOR III trial, which is currently enrolling and is designed to assure high-quality evidence by implementing a pretrial showing surgical competency, central review of MRI, assessment of procedural video, re-evaluation of the specimen and obligatory upload and central review of MRI 3 years after surgery [28].

\section{Conclusions}

TaTME is associated with relatively low local recurrence rate at 3 years and 5 years. This shows that in experienced hands with high volume, TaTME is safe and is associated with good long-term outcome.

\section{Compliance with ethical standards}

Conflict of interest The authors declare that they have no conflict of interest.

Ethical approval The study was approved by the Ethics Committees of the participating centers. All procedures performed in studies involving human participants were in accordance with the ethical standards of the institutional and/or national research committee and with the 1964 Helsinki Declaration and its later amendments or comparable ethical standards.

Informed consent Informed consent was not required for this type of study.

Open Access This article is distributed under the terms of the Creative Commons Attribution 4.0 International License (http://creativeco mmons.org/licenses/by/4.0/), which permits unrestricted use, distribution, and reproduction in any medium, provided you give appropriate credit to the original author(s) and the source, provide a link to the Creative Commons license, and indicate if changes were made.

\section{References}

1. Sylla P et al (2010) NOTES transanal rectal cancer resection using transanal endoscopic microsurgery and laparoscopic assistance. Surg Endosc 24(5):1205-1210

2. Helbach MV et al (2016) Transanal total mesorectal excision for rectal carcinoma: short-term outcomes and experience after 80 cases. Surg Endosc 30(2):464-470

3. Deijen CL et al (2016) Clinical outcomes and case volume effect of transanal total mesorectal excision for rectal cancer: a systematic review. Tech Coloproctol 20(12):811-824

4. Zhang X et al (2019) Short- and long-term outcomes of transanal versus laparoscopic total mesorectal excision for mid-to-low rectal cancer: a meta-analysis. Surg Endosc 33(3):972-985

5. Heald RJ, Husband EM, Ryall RD (1982) The mesorectum in rectal cancer surgery-the clue to pelvic recurrence? Br J Surg 69(10):613-616

6. Bonjer $\mathrm{HJ}$ et al (2015) A randomized trial of laparoscopic versus open surgery for rectal cancer. N Engl J Med 373(2):194

7. Stevenson ARL et al (2019) Disease-free survival and local recurrence after laparoscopic-assisted resection or open resection for rectal cancer: the Australasian laparoscopic cancer of the rectum randomized clinical trial. Ann Surg 269(4):596-602

8. Fleshman J et al (2019) Disease-free survival and local recurrence for laparoscopic resection compared with open resection of stage ii to iii rectal cancer: follow-up results of the ACOSOG Z6051 randomized controlled trial. Ann Surg 269(4):589-595

9. Koedam TWA et al (2018) Transanal total mesorectal excision for rectal cancer: evaluation of the learning curve. Tech Coloproctol 22(4):279-287

10. Larsen SG et al (2019) Norwegian moratorium on transanal total mesorectal excision. Br J Surg 106(9):1120-1121

11. Lelong B et al (2017) Short- and mid-term outcomes after endoscopic transanal or laparoscopic transabdominal total mesorectal excision for low rectal cancer: a single institutional casecontrol study. J Am Coll Surg 224(5):917-925

12. Burke JP et al (2016) Transanal total mesorectal excision for rectal cancer: early outcomes in 50 consecutive patients. Colorectal Dis 18(6):570-577

13. Lacy AM et al (2015) Transanal total mesorectal excision for rectal cancer: outcomes after 140 patients. J Am Coll Surg 221(2):415-423

14. Rouanet $P$ et al (2013) Transanal endoscopic proctectomy: an innovative procedure for difficult resection of rectal tumors in men with narrow pelvis. Dis Colon Rectum 56(4):408-415

15. de'Angelis N et al (2015) Transanal total mesorectal excision for rectal cancer: a single center experience and systematic review of the literature. Langenbecks Arch Surg 400(8):945-959

16. Kusters $M$ et al (2010) Patterns of local recurrence in rectal cancer; a study of the Dutch TME trial. Eur J Surg Oncol 36(5):470-476

17. Nagtegaal ID et al (2002) Macroscopic evaluation of rectal cancer resection specimen: clinical significance of the pathologist in quality control. J Clin Oncol 20(7):1729-1734 
18. Velthuis $\mathrm{S}$ et al (2014) Transanal versus traditional laparoscopic total mesorectal excision for rectal carcinoma. Surg Endosc 28(12):3494-3499

19. van Oostendorp SE et al (2018) Transanal total mesorectal excision compared to laparoscopic TME for mid and low rectal cancer-current evidence. Ann Laparosc Endosc Surg 3(5):41-49

20. Adamina M et al (2018) St. Gallen consensus on safe implementation of transanal total mesorectal excision. Surg Endosc 32(3):1091-1103

21. Helbach MV et al (2019) Structured training pathway and proctoring; multicenter results of the implementation of transanal total mesorectal excision (TaTME) in The Netherlands. Surg Endosc. https://doi.org/10.1007/s00464-019-06750-w

22. Abbott SC et al (2018) An assessment of an Australasian pathway for the introduction of transanal total mesorectal excision (taTME). Colorectal Dis 20(1):O1-O6

23. Lee L et al (2018) Establishing the learning curve of transanal minimally invasive surgery for local excision of rectal neoplasms. Surg Endosc 32(3):1368-1376

24. Perdawood SK (2018) A case of local recurrence following transanal total mesorectal excision: a new form of port-site metastasis? Tech Coloproctol 22(4):319-320
25. McCulloch P et al (2009) No surgical innovation without evaluation: the IDEAL recommendations. Lancet 374(9695):1105-1112

26. Wexner SD, Cohen SM (1995) Port site metastases after laparoscopic colorectal surgery for cure of malignancy. Br J Surg 82(3):295-298

27. Penna $\mathrm{M}$ et al (2019) Incidence and risk factors for anastomotic failure in 1594 patients treated by transanal total mesorectal excision: results from the international TaTME registry. Ann Surg 269(4):700-711

28. Deijen CL et al (2016) COLOR III: a multicentre randomised clinical trial comparing transanal TME versus laparoscopic TME for mid and low rectal cancer. Surg Endosc 30(8):3210-3215

Publisher's Note Springer Nature remains neutral with regard to jurisdictional claims in published maps and institutional affiliations. 